Supporting information for

\title{
Metal-Organic Framework-Intercalated Graphene Oxide Membranes for Selective Separation of Uranium
}

Tianqi Liu, ${ }^{\dagger, £}$ Zhan Li,,${ }^{\ddagger}{ }^{*}$ Xin Zhang, ${ }^{£}$ Hongxin Tan,${ }^{\dagger}$ Ziying Chen,${ }^{\dagger}$ Jinsheng Wu,${ }^{\dagger}$ Jia Chen, ${ }^{\dagger}$ Hongdeng Qiu ${ }^{\dagger, \S, \&, *}$

${ }^{\dagger}$ CAS Key Laboratory of Chemistry of Northwestern Plant Resources and Key Laboratory for Natural Medicine of Gansu Province, Lanzhou Institute of Chemical Physics, Chinese Academy of Sciences, Lanzhou 730000, China.

Institute of National Nuclear Industry, Lanzhou University, Lanzhou, 730000, China.

${ }^{£}$ School of Nuclear Science and Technology, Lanzhou University, Lanzhou, 730000, China.

$\S$ College of Chemistry, Zhengzhou University, Zhengzhou, 450001, China.

${ }^{\&}$ College of Chemistry and Chemical Engineering, Gannan Normal University, Ganzhou 341000, China.

*Corresponding author: liz@1zu.edu.cn (Z. Li); hdqiu@licp.cas.cn.com (H. Qiu)

Table of Contents

1. Experimental.

2. Characterizations of BTC-MOF.

3. Characterizations and separation performance of BTC-MOF intercalated graphene membrane. 


\section{Experimental}

\subsection{Preparation of BTC-MOF}

Table S1 Prepare BTC-MOF weighing list

\begin{tabular}{ccccc}
\hline BTC-MOF & Nitrate & $\mathbf{m}_{\text {Nitrate }}(\mathbf{g})$ & $\mathbf{m}_{\text {Trimesic acid }}(\mathbf{g})$ & $\mathbf{V}_{\text {DMF }}(\mathbf{m L})$ \\
\hline $\mathrm{Cu}-\mathrm{BTC}-\mathrm{MOF}$ & $\mathrm{Cu}\left(\mathrm{NO}_{3}\right)_{2} \cdot 6 \mathrm{H}_{2} \mathrm{O}$ & 0.8456 & 1.4708 & 40 \\
$\mathrm{Zn}-\mathrm{BTC}-\mathrm{MOF}$ & $\mathrm{Zn}\left(\mathrm{NO}_{3}\right)_{2} \cdot 6 \mathrm{H}_{2} \mathrm{O}$ & 0.5206 & 0.7355 & 40 \\
$\mathrm{Ni}-\mathrm{BTC}-\mathrm{MOF}$ & $\mathrm{Ni}\left(\mathrm{NO}_{3}\right)_{2} \cdot 6 \mathrm{H}_{2} \mathrm{O}$ & 1.0179 & 1.4708 & 40 \\
\hline
\end{tabular}

\subsection{The preparation of the GO}

The modified Hummers method was used to prepare GO. ${ }^{1}$ In 5 g graphite powder, $5 \mathrm{~g} \mathrm{NaNO}$ was added, $200 \mathrm{~mL}$ concentrated sulfuric acid was added slowly, and the reaction was carried out at low temperature for $1 \mathrm{~h}$. Then, $20 \mathrm{~g} \mathrm{KMnO}_{4}$ was slowly added and reacted at $38 \square$ for 26 hours. And then $250 \mathrm{~mL}$ of deionized water was added and reacted at $84 \square$ for 15 minutes. After the reaction, pour it into $500 \mathrm{~mL}$ of deionized water. The reaction was terminated by adding $30 \% \mathrm{H}_{2} \mathrm{O}_{2}$. Washed with 10\% hydrochloric acid for 3-4 times. Then washed it with deionized water until it is neutral. It could get graphene oxide.

\subsection{Separating device}




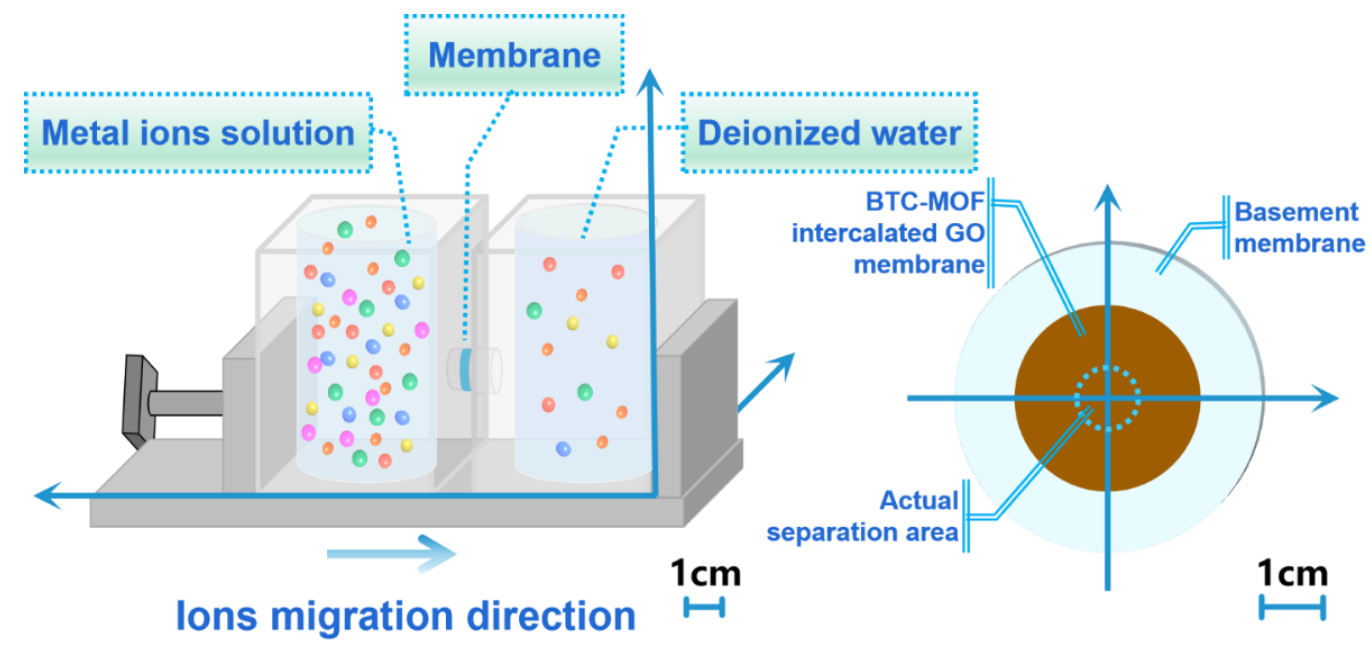

Figure S1. Membrane separation device diagram. The left side is the diagram of the separation device, and the right side is the schematic diagram of the separation membrane.

\subsection{Kinetic experiment calculation}

The $\mathrm{K}^{+} 、 \mathrm{Fe}^{3+}$ ion data is detected by atomic absorption spectrometer (AAS), and its throughput is calculated by the formula S1:

$$
J=\frac{C_{n} \times[0.1-0.006(n-1)]}{A}
$$

$\boldsymbol{J}$ represents the amount of permeation, the unit is $\mathrm{mol} \cdot \mathrm{m}^{-2} ; \boldsymbol{C}_{\boldsymbol{n}}$ represents the concentration of the test solution, the unit is $m o l \cdot L^{-1} ; \boldsymbol{n}$ represents the number of samples; $\boldsymbol{A}$ represents the effective area of separation, the unit is $m^{-2}$.

\subsection{Condition optimization experiment}

Different nitrate solutions $\left(0.01 \mathrm{~mol} \cdot \mathrm{L}^{-1}\right)$ including $\mathrm{K}^{+}, \mathrm{Cu}^{2+}$ and $\mathrm{Fe}^{3+}$ were prepared first, and then 0.4 / $0.04 \mathrm{M}$ nitric acid and 0.4 / $0.04 \mathrm{M}$ ammonia was used to adjust the $\mathrm{pH}$ of the solution to 2.0, 2.3, 3.0, 3.5. According to different experimental conditions, the separation membrane is placed in the middle of the separation device (Figure S1), with $100 \mathrm{~mL}$ of the solution to be separated on the left and $100 \mathrm{~mL}$ of deionized water on the right. The separation is carried out under stirring at room 
temperature. Take an equal volume of sample solution on the left and right sides at the same time, and then use AAS to detect the ion concentration in the solution on the right.

\section{Characterizations of BTC-MOF.}

Figure S2 was the XRD characterization of different BTC-MOF and graphene oxide. The $2 \theta$ values of $\mathrm{Zn-BTC-MOF}$ were in the range of $5-40^{\circ}$, at $9.2^{\circ}, 10.1^{\circ}, 14.9^{\circ}, 15.7^{\circ}, 17.8^{\circ}, 19.1^{\circ}$ diffraction patterned appear at $24.7^{\circ}$. Compared with the XRD patterns reported in the literature, ${ }^{2}$ the change of some diffraction peaks may be due to the difference in temperature conditions selected during the reaction, which caused some peaks to shift. The $2 \theta$ in Ni-BTC-MOF had characteristic peaks at $13^{\circ}, 15^{\circ}, 17.7^{\circ}, 18.9^{\circ}, 21.3^{\circ}, 23^{\circ}$, which was basically consistent with other literature. ${ }^{3}$ The $2 \theta$ values of $\mathrm{Cu}-\mathrm{BTC}-\mathrm{MOF}$ had characteristic peaks at $6.6^{\circ}, 9.4^{\circ}, 11.5^{\circ}, 13.4^{\circ}$, and $18.9^{\circ}$, which were consistent with the XRD pattern of $\mathrm{Cu}-\mathrm{BTC}-\mathrm{MOF}$ reported in the literature. ${ }^{4}$ It can be seen that there was a characteristic peak of graphene oxide [001] at around $11.5^{\circ}$.

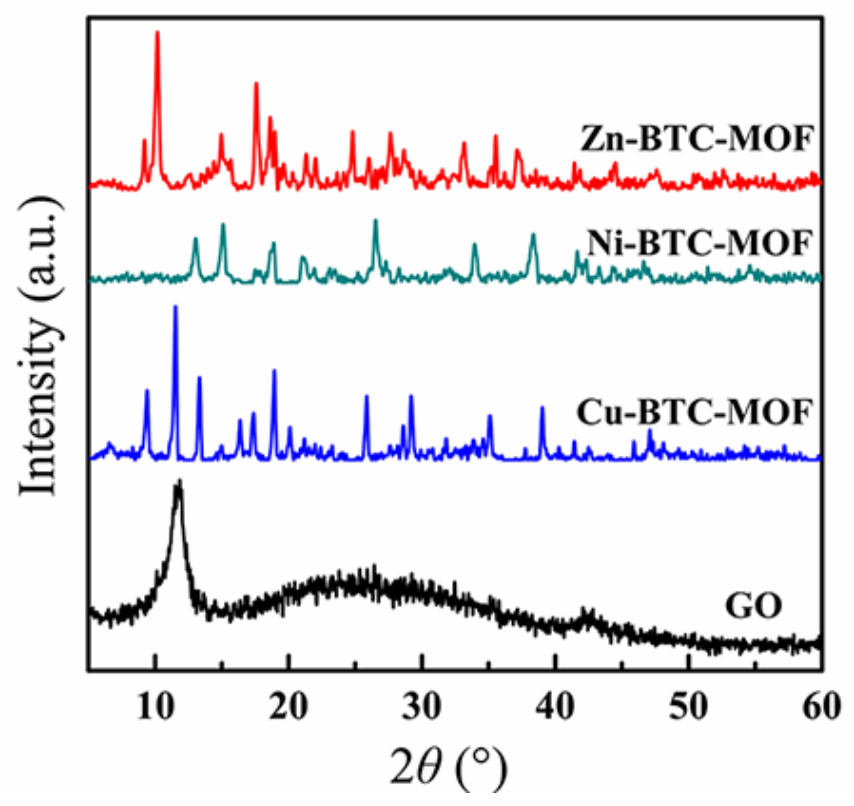

Figure S2. XRD of Zn-BTC-MOF, Ni-BTC-MOF, Cu-BTC-MOF and GO. 
Figure S3 shown the FT-IR of graphene oxide and different BTC-MOFs. Graphene oxide had $\mathrm{C}-\mathrm{OH}$ at $1060 \mathrm{~cm}^{-1}$ and $1376 \mathrm{~cm}^{-1}, \mathrm{C}=\mathrm{C}$ peak at $1621 \mathrm{~cm}^{-1}, \mathrm{C}=\mathrm{O}$ peak at $1721 \mathrm{~cm}^{-1}$, and $3415 \mathrm{~cm}^{-1}$ $\mathrm{O}-\mathrm{H}$ peak, there was a weak $\mathrm{O}=\mathrm{C}-\mathrm{O}-\mathrm{C}$ peak at $1274 \mathrm{~cm}^{-1}$, and a weak $\mathrm{C}-\mathrm{O}$ peak at $1221 \mathrm{~cm}^{-1}$. The spectra of different BTC-MOFs were basically the same. A very broad O-H peak was formed at 3000$3700 \mathrm{~cm}^{-1}$ in the complex, which indicates that there were loosely bound water molecules in the BTCMOF material. There are $\mathrm{C}=\mathrm{O}$ stretching vibration peaks at 1629 and $1580 \mathrm{~cm}^{-1}, \mathrm{C}-\mathrm{O}$ stretching vibration peaks at 1442 and $1377 \mathrm{~cm}^{-1}$, and a C-O-C stretching vibration band at $1106 \mathrm{~cm}^{-1}$. The characteristic vibration peak at $759 \mathrm{~cm}^{-1}$ may be caused by the coordination of metal atoms and $\mathrm{O}$ atoms to form $\mathrm{M}-\mathrm{O}(\mathrm{M}=\mathrm{Zn}, \mathrm{Cu}, \mathrm{Ni})$ stretching vibrations.

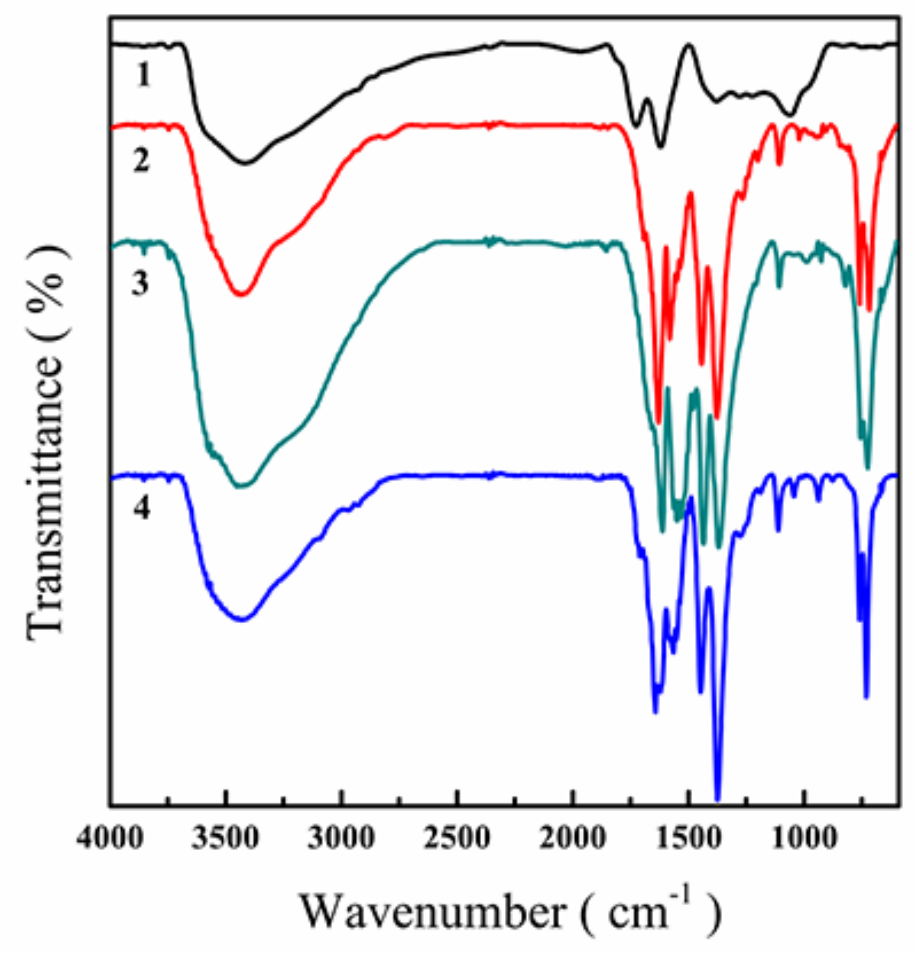

Figure S3. FT-IR characterization of 1. GO, 2. Zn-BTC-MOF, 3. Ni-BTC-MOF, 4. Cu-BTC-MOF.

Figure S4 and Table S2 was an illustration of the $\mathrm{N}_{2}$ adsorption and desorption curves of different BTC-MOFs and their pore size distribution. BET calculation was carried out based on the data. The 
specific surface area of the Zn-BTC-MOF material was $4.6277 \mathrm{~m}^{2} \cdot \mathrm{g}^{-1}$, and the pore size distribution of the material was approximately at about $10 \mathrm{~nm}$. The specific surface area of Ni-BTC-MOF material was $1.3454 \mathrm{~m}^{2} \cdot \mathrm{g}^{-1}$, and the pore size distribution of the material was about $20 \mathrm{~nm}$. The specific surface area of $\mathrm{Cu}$-BTC-MOF material was $1072.7852 \mathrm{~m}^{2} \cdot \mathrm{g}^{-1}$, and the material pore size was about $2 \mathrm{~nm}$. Among them, Cu-BTC-MOF has the largest specific surface area, but its pore size was the smallest, and Ni-BTC-MOF material had the smallest specific surface area, but its pore size was the largest, which had a certain impact on the separation and application of materials.
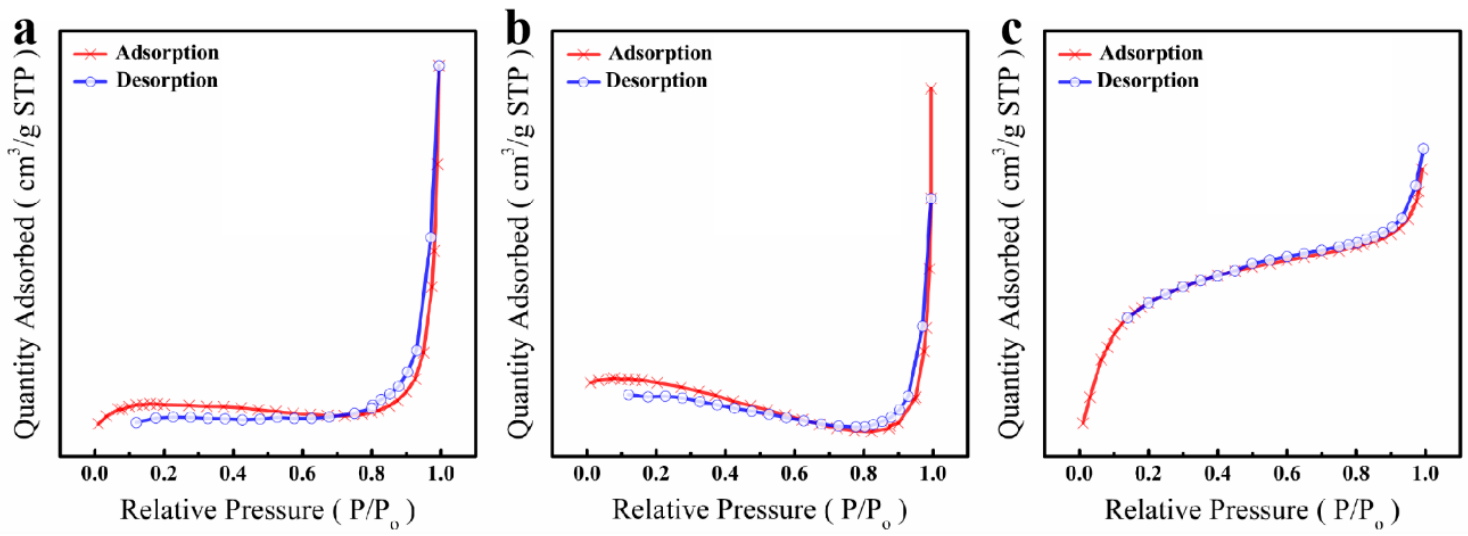

Figure S4. The $\mathrm{N}_{2}$ adsorption-desorption measurements of (a) Zn-BTC-MOF, (b) Ni-BTC-MOF, (c) Cu-BTC-

MOF.

Table S2 Pore size distribution and specific surface area of BTC-MOF

\begin{tabular}{ccc}
\hline BTC-MOF & $\begin{array}{r}\text { Pore size distribution } \\
(\mathbf{n m})\end{array}$ & $\begin{array}{c}\text { Specific surface area } \\
\left(\mathbf{m}^{\mathbf{2}} \cdot \mathbf{g}^{-\mathbf{1}} \mathbf{)}\right.\end{array}$ \\
\hline Zn-BTC-MOF & $\sim 20$ & 4.6277 \\
Ni-BTC-MOF & $\sim 10$ & 1.3454 \\
Cu-BTC-MOF & $\sim 2$ & 1072.7852 \\
\hline
\end{tabular}




\section{Characterizations and separation performance of BTC-MOF intercalated}

\section{graphene membrane.}

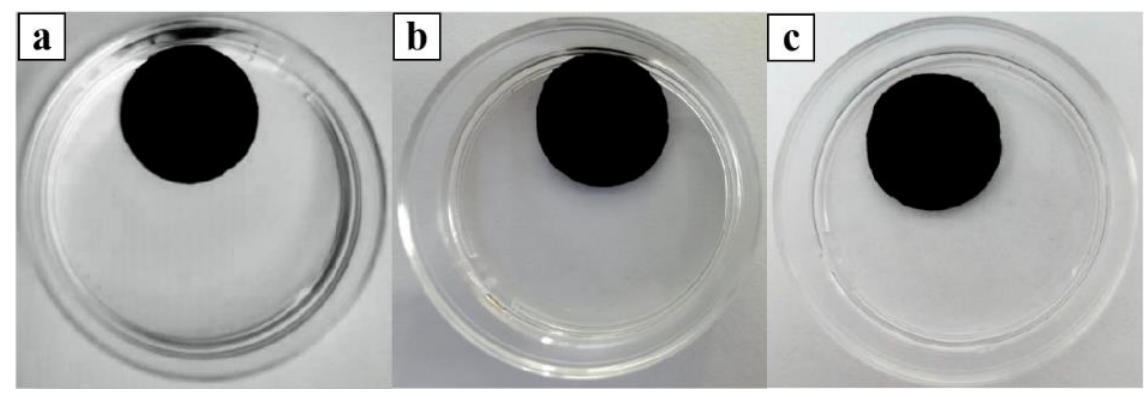

Figure S5 (a-c) The images of Zn-BTC-MOF intercalated GO membranes immersed in an acidic solution with $\mathrm{pH}=2.3$ for $0 \mathrm{~h}, 12 \mathrm{~h}$ and $24 \mathrm{~h}$, respectively.

Figure S6 shown the contact angle experiment results of Zn-BTC-MOF intercalated graphene oxide membranes prepared with different mass ratios of graphene oxide and MOF. The experimental results shown that the BTC-MOF intercalated graphene oxide membrane was a hydrophilic membrane. When the content of graphene oxide and MOF are the same, the hydrophilic performance of the membrane material was the best. When the content of graphene oxide was large, the hydrophilicity of the membrane material was better. The reason for this phenomenon may be due to the increase in the content of graphene oxide. Increased. The layer-by-layer structure of graphene oxide affected the water absorption performance of the membrane material, thereby increasing the contact angle; when MOF materials were predominant, the hydrophilicity of the membrane material decreases, which may be caused by the increase in MOF materials in order to reduce the water absorption performance, the contact angle increases and the hydrophilic performance decreases. 


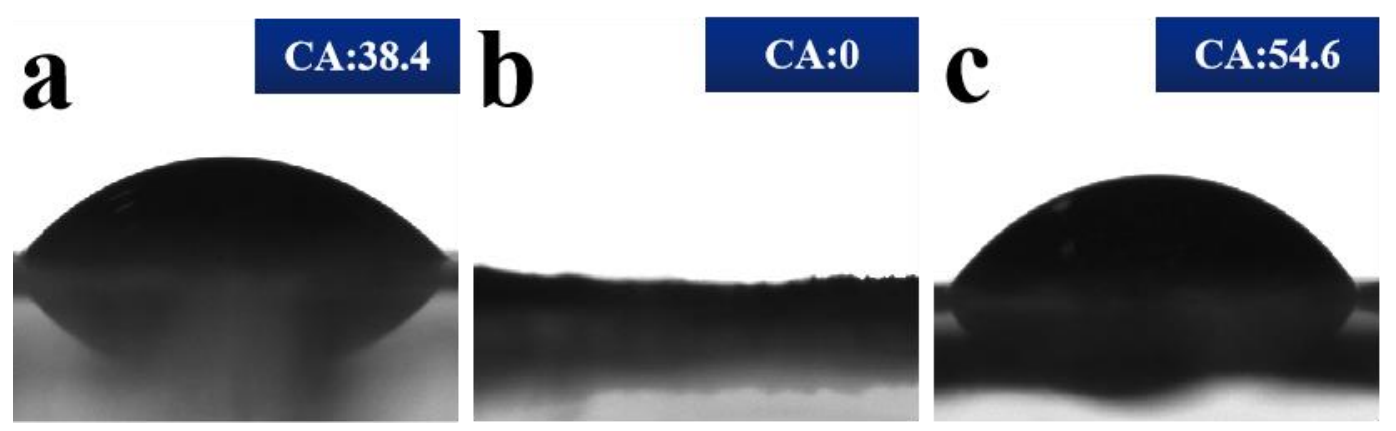

Figure S6. GO and MOF different mass ratio of the membrane material contact angle experiment: (a) $m_{\mathrm{GO}}: m_{\mathrm{MOF}}=4: 1$, (b) $m_{\mathrm{GO}}: m_{\mathrm{MOF}}=1: 1$, (c) $m_{\mathrm{GO}}: m_{\mathrm{MOF}}=1: 4$.

Table S3 The separation factors for separation of different valence metal ions by the membrane separation of graphene oxide and MOF with different mass ratios

\begin{tabular}{cccc}
\hline Membrace & $\mathrm{SF}_{(\mathrm{K} / \mathrm{Cu})}$ & $\mathrm{SF}(\mathrm{K} / \mathrm{Fe})$ & $\mathrm{SF}(\mathrm{Cu} / \mathrm{Fe})$ \\
\hline $\mathrm{m}_{\mathrm{GO}}: \mathrm{m}_{\mathrm{MOF}}=4: 1$ & 32.51 & 502.56 & 15.46 \\
$\mathrm{~m}_{\mathrm{GO}}: \mathrm{m}_{\mathrm{MOF}}=1: 1$ & 39.64 & 1075.49 & 27.13 \\
$\mathrm{~m}_{\mathrm{GO}}: \mathrm{m}_{\mathrm{MOF}}=1: 0$ & 7.09 & 29.79 & 4.20 \\
$\mathrm{~m}_{\mathrm{GO}}: \mathrm{m}_{\mathrm{MOF}}=1: 4$ & 13.90 & 94.28 & 6.78 \\
\hline
\end{tabular}

Table S4 The separation factors for separation of heavy different valence metal ions by different pH solution conditions

\begin{tabular}{cccc}
\hline Membrace & $\mathrm{SF}_{(\mathrm{K} / \mathrm{Cu})}$ & $\mathrm{SF}_{(\mathrm{K} / \mathrm{Fe})}$ & $\mathrm{SF}_{(\mathrm{Cu} / \mathrm{Fe})}$ \\
\hline $\mathrm{pH}=2$ & 16.01 & 142.68 & 8.91 \\
$\mathrm{pH}=2.3$ & 39.64 & 1075.49 & 27.13 \\
$\mathrm{pH}=3$ & 3.51 & 434.54 & 123.83 \\
$\mathrm{pH}=3.5$ & 4.12 & 333.92 & 81.05 \\
\hline
\end{tabular}


Table S5 The separation factors for separation of different valence metal ions by different thicknesses membranes

\begin{tabular}{cccc}
\hline Membrace & $\mathrm{SF}_{(\mathrm{K} / \mathrm{Cu})}$ & $\mathrm{SF}(\mathrm{K} / \mathrm{Fe})$ & $\mathrm{SF}(\mathrm{Cu} / \mathrm{Fe})$ \\
\hline $\mathrm{V}=1 \mathrm{~mL}$ & 39.64 & 1075.49 & 27.13 \\
$\mathrm{~V}=2 \mathrm{~mL}$ & 62.32 & 785.02 & 12.60 \\
$\mathrm{~V}=3 \mathrm{~mL}$ & 18.27 & 404.51 & 22.14 \\
\hline
\end{tabular}

Table S6 The separation factors for separation of different valence metal ions by different BTC-MOF intercalated GO membranes

\begin{tabular}{cccc}
\hline Membrace & $\mathrm{SF}_{(\mathrm{K} / \mathrm{Cu})}$ & $\mathrm{SF}_{(\mathrm{K} / \mathrm{Fe})}$ & $\mathrm{SF}(\mathrm{Cu} / \mathrm{Fe})$ \\
\hline Zn-BTC-MOF & 39.64 & 1075.49 & 27.13 \\
Ni-BTC-MOF & 6.79 & 356.80 & 51.06 \\
Cu-BTC-MOF & 3.81 & 5.62 & 1.47 \\
\hline
\end{tabular}

The Zn-BTC-MOF intercalated graphene oxide membrane separation radioactive element rear membrane surface SEM-EDS elemental mapping as shown in Figure S7. It can be seen from the surface element distribution content, the content of $\mathrm{C}$ and $\mathrm{O}$ elements was the highest, proved the surface of the membrane was graphene oxide. Some $\mathrm{Zn}$ elements were present because the membrane surface may contained a small amount of Zn-BTC-MOF material. In the isolated element, the content of the Cs was at least, which was the highest passage of the permeability of the membrane. The content of Th was mostly in the membrane surface, and $\mathrm{Th}^{4+}$ may adsorb the surface of the membrane, which was not analyzed, so the transmission amount was relatively low. The U content was also more in the surface of the membrane, but the amount of transmittance was also relatively high, which may 
be because $\mathrm{UO}_{2}{ }^{2+}$ first adsorbed on the membrane, and then analyzes, thereby penetrating into the right solution by the membrane.

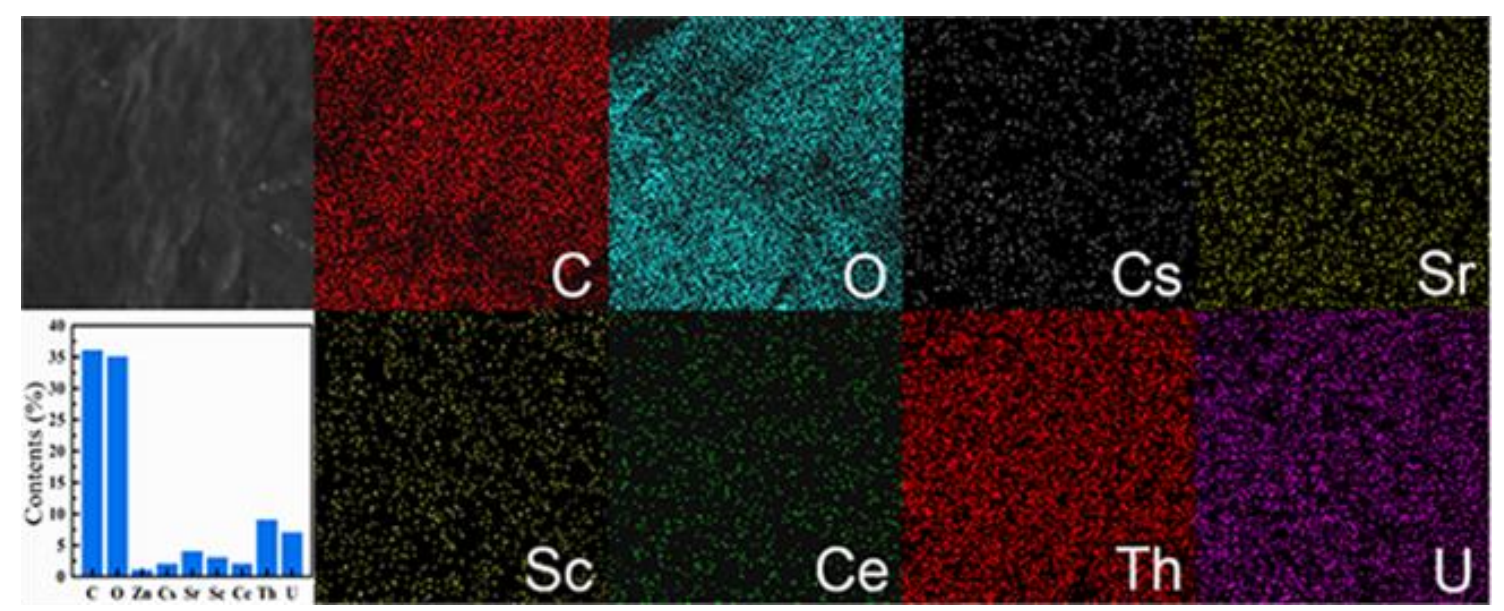

Figure S7. Separation of radioactive elements Zn-BTC-MOF intercalated graphene oxide membrane surface SEM-EDS elemental mapping.

The Zn-BTC-MOF intercalated graphene oxide membrane material was separated and the membrane XPS was characterized as shown in Figure S8, and the C-element XPS peak resulted in the Figure S8a, $\mathrm{C}-\mathrm{C} / \mathrm{C}=\mathrm{C}, \mathrm{C}-\mathrm{O}-\mathrm{C}, \mathrm{O}-\mathrm{C}=\mathrm{O}$ key. The Figure $\mathrm{S} 8 \mathrm{~b}$ was the peak result of the $\mathrm{O}$ element XPS, the results of O-H, C-O keys, $\mathrm{C}$ and $\mathrm{O}$ elements in the membrane material were consistent with the results of the FT-IR. The Figure S8c was the XPS peak case of Zn element, there was Zn-O key, because there was a Zn-BTC-MOF material in the membrane material, there was a bond key of $\mathrm{Zn}$ and O. Cs (Figure S8d), Sr (Figure S8e), Sc (Figure S8f), Th (Figure S8h), it can be seen in the form of a metal element in the membrane, and there was a single metallic peak. The Figure S8g was the XPS peak result of the Ce element, and found that the XPS results of the Ce were linear, inconstant. The peak appeared, indicating that there was a small amount or this did not exist in the Zn-BTC-MOF insertion oxide insertion, resulting in the detection process, which may be because the membrane pair 
during the separation process the adsorption capacity of $\mathrm{Ce}^{3+}$ was weak. And $\mathrm{Ce}^{3+}$ can penetrate directly to the right solution between the pore or MOF between the membrane layers. In the Figure S8i, the XPS peak result of the $\mathrm{U}$ element was penetrated, and $\mathrm{UO}_{2}{ }^{2+}$ was combined with $\mathrm{O}$, forming $\mathrm{UO}_{3}$, forming $\mathrm{UO}_{3}$. The portion $\mathrm{UO}_{2}{ }^{2+}$ was also combined with $\mathrm{Cs}^{+}$, forming $\mathrm{Cs}_{3} \mathrm{UO}_{4}$ and $\mathrm{Cs}_{2} \mathrm{U}_{2} \mathrm{O}_{7}$, but the peak intensity combined with $\mathrm{Cs}^{+}$was low, so the content was low, and there was $\mathrm{UO}_{2}\left(\mathrm{NO}_{3}\right)_{2} \cdot 6 \mathrm{H}_{2} \mathrm{O}$ compound on the membrane, which was present in the original solution. Therefore, there was also a certain possibility on the membrane.
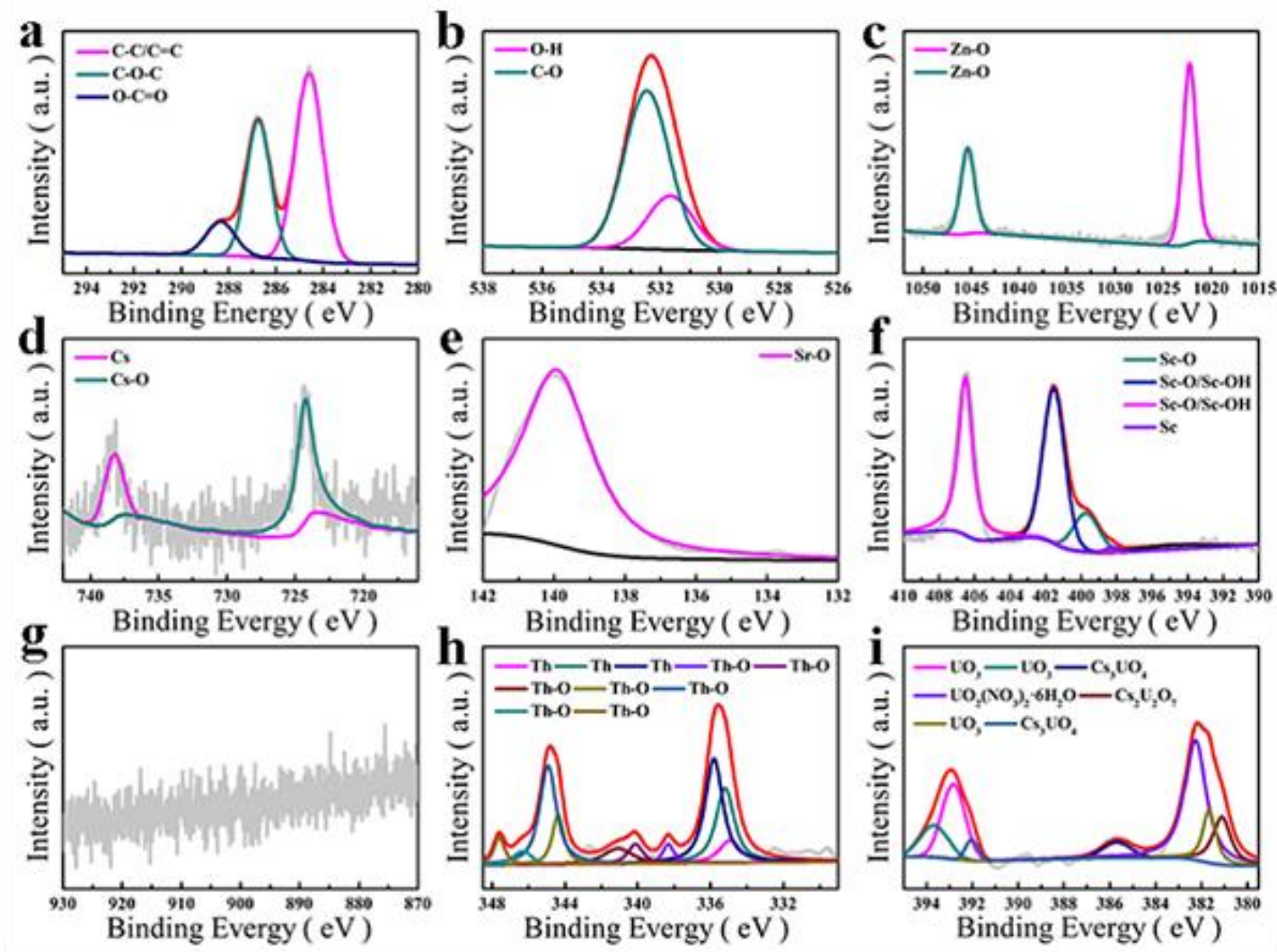

Figure S8. XPS characterization of the separated radioactive element Zn-BTC-MOF intercalated graphene oxide membrane (a. C; b. O; c. Zn; d. Cs; e. Sr; f. Sc; g. Ce; h . Th; i. U)

The Ni-BTC-MOF intercalated graphene oxide membrane material separated radioactive element after membrane surface SEM-EDS elemental mapping as shown in Figure S9. From the membrane surface element distribution content, It can be seen the content of $\mathrm{C}$ and $\mathrm{O}$ elements was 
the highest, prove the surface of the membrane is oxide. Some Ni elements were present because the surface of the membrane may contain a small amount of Ni-BTC-MOF material. In the isolated element, the content of the Cs was at least, which was the highest passage of the permeability of the membrane. The content of Th was mostly in the membrane surface, and $\mathrm{Th}^{4+}$ may adsorb the surface of the membrane, which was not analyzed, so the transmission amount was relatively low. The U content was also more in the surface of the membrane, but the amount of transmittance was also relatively high, which may be because $\mathrm{UO}_{2}{ }^{2+}$ first adsorbed on the membrane, and then analyzes, thereby penetrating into the right solution by the membrane.

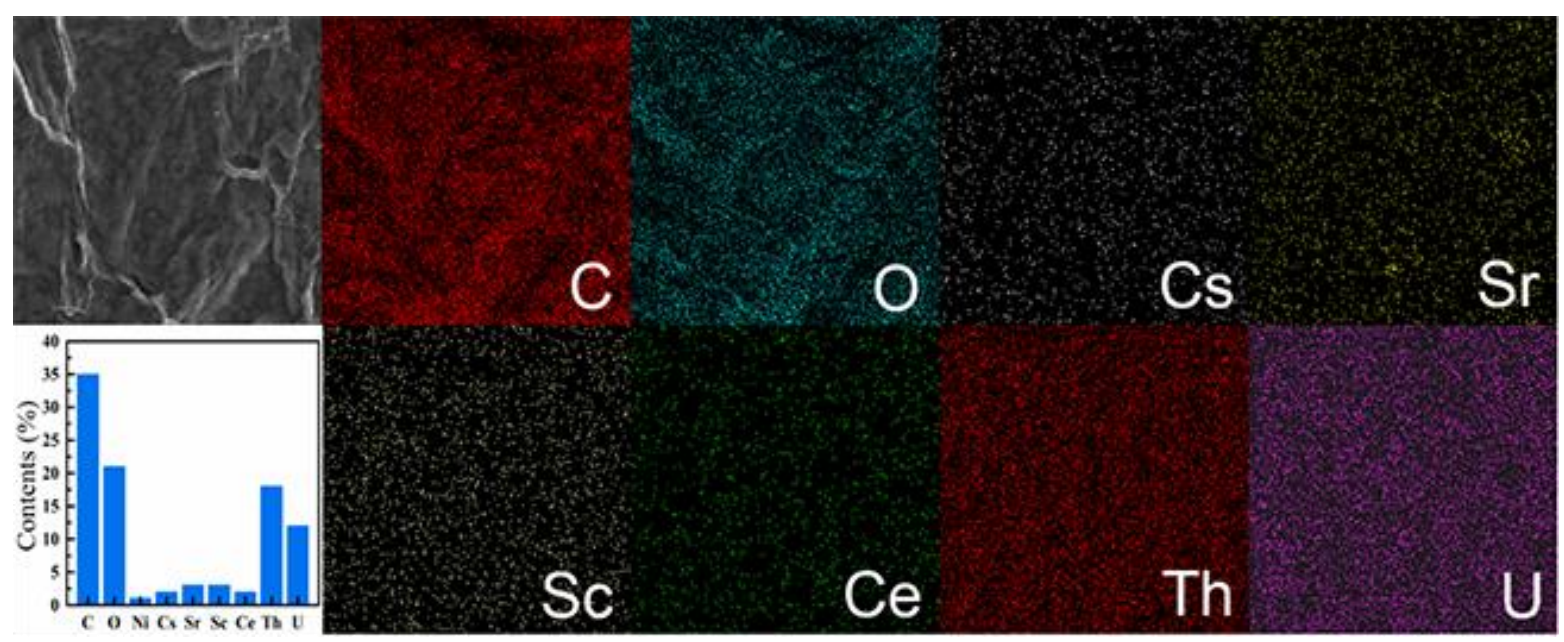

Figure S9. Separation of radioactive elements Ni-BTC-MOF intercalated graphene oxide membrane surface SEM-EDS elemental mapping.

The Ni-BTC-MOF intercalated graphene oxide membrane was separated from the membrane XPS characterization as shown in Figure S10. The C-element XPS peak results in the Figure S10a, and $\mathrm{C}-\mathrm{C} / \mathrm{C}=\mathrm{C}, \mathrm{C}-\mathrm{O}-\mathrm{C}, \mathrm{C}=\mathrm{O}, \mathrm{O}-\mathrm{C}=\mathrm{O}$ binding bond; Figure $\mathrm{S} 10 \mathrm{~b}$ was the peak result of $\mathrm{O}$ element XPS peak, and the results of $\mathrm{O}-\mathrm{H}, \mathrm{C}-\mathrm{O}$ keys, $\mathrm{C}$ and $\mathrm{O}$ elements in the membrane material were consistent with the results of infrared spectrum. The Figure S10c was the XPS peak of Ni elements. Situation, this element did not have a level peak during the detection process, which may be due to 
fewer content of Ni-BTC-MOF in the membrane material, or less of the Ni element content in the local range. Figure S10d was Cs element XPS, from the results, the occurrence of unopened characteristic peaks, indicating that the content of the membrane surface Cs element did not reach the detection limit, which may not be detected together, which may be that $\mathrm{Cs}^{+}$was not adsorbed on the membrane, directly passing the membrane interlayer pore in the right solution. Sr (Figure S10e), Sc (Figure S10f), Th (Figure S10h) XPS peak results can be seen in the form of a metal element in combination with O. The Figure S10g was the XPS peak result of the Ce element. It was found that the XPS results of the Ce were linear, and the inability-level peaks appeared. Description on the NiBTC-MOF intercalated graphene oxide membrane, there was a small amount or does not have a Ce element. It may result in a peak in the detection process, which may be because the membrane had a weak adsorption capacity of $\mathrm{Ce}^{3+}$ during the separation, and $\mathrm{Ce}^{3+}$ can penetrate to the right solution by the pore or MOF of the membrane layer. In the Figure S10i XPS peak result of the U element, $\mathrm{UO}_{2}{ }^{2+}$ was combined with $\mathrm{O}$, forming $\mathrm{UO}_{3}$, and the portion of the $\mathrm{U}$ element exhibits $\mathrm{UO}_{2}\left(\mathrm{NO}_{3}\right)_{2} \cdot 6 \mathrm{H}_{2} \mathrm{O}$ compound, which was present in the original solution, so on the membrane is also had a certain possibility of detecting. 

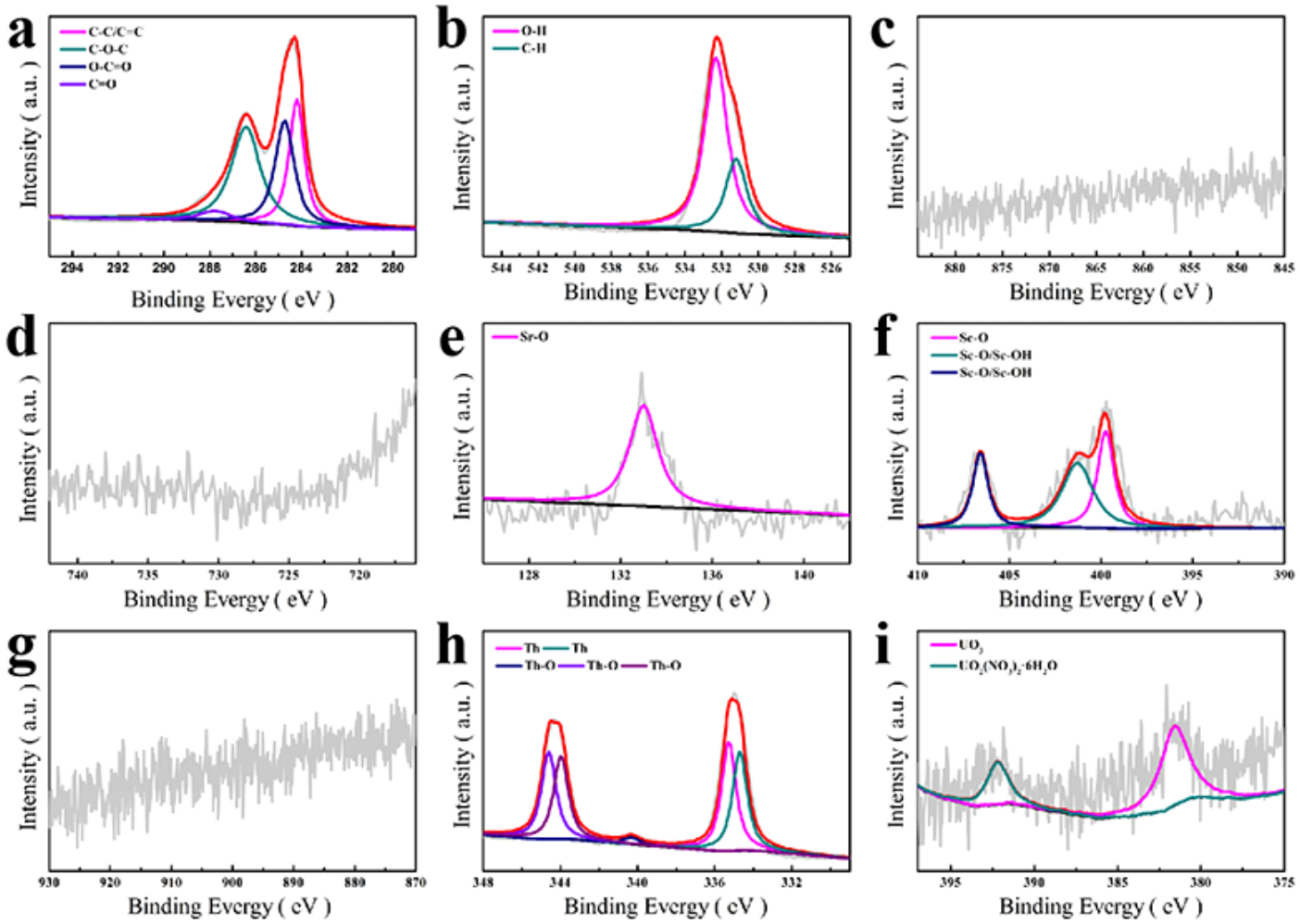

Figure S10. XPS characterization of the separated radioactive element Ni-BTC-MOF intercalated graphene oxide membrane (a. C; b. O; c. Ni; d. Cs; e. Sr; f. Sc; g. Ce; h. Th; i. U)

The $\mathrm{Cu}-\mathrm{BTC}-\mathrm{MOF}$ intercalated graphene oxide membrane material separation radioactive element was characterized as shown in Figure S11. The C-element XPS peak results in the Figure S11a, $\mathrm{C}-\mathrm{C} / \mathrm{C}=\mathrm{C}, \mathrm{C}-\mathrm{O}-\mathrm{C}, \mathrm{C}=\mathrm{O}$ binding key. Figure $\mathrm{S} 11 \mathrm{~b}$ was the peak result of the $\mathrm{O}$ element XPS, the result of $\mathrm{O}-\mathrm{H}, \mathrm{C}-\mathrm{O}$ keys, $\mathrm{C}$ and $\mathrm{O}$ elements in the membrane material was consistent with the results of the infrared spectrum. The Figure S11c was $\mathrm{Cu}$ element XPS peak, there was no energy level peak during the test, which may be due to fewer content of $\mathrm{Cu}-\mathrm{BTC}-\mathrm{MOF}$ in the membrane material, or at least the $\mathrm{Cu}$ element content in the local range. Cs (Figure S11d), Sr (Figure S11e), Sc (Figure S11f) and Th (Figure S11h) can be seen in the form of the metal element in the form of the combination of and O. And some of the monolithic peaks, where in the Sc elements were in the membrane. Detected, but in the separation process, $\mathrm{Sc}^{3+}$ did not penetrate to the right side of the solution, which may be because there was a small amount of $\mathrm{Sc}^{3+}$ in the separation process on the 
membrane, but the membrane was not translated by it. Figure S11g was shown the Ce element XPS peak results found that the XPS results of the Ce were linear, indicating that there was a lower than the detection limit or the $\mathrm{Ce}$ element in the $\mathrm{Cu}$-BTC-MOF intercalated graphene oxide membrane, resulting in the detection process. The peak, which may be because the membrane was weak during the separation process, and the right solution in the isolation result was not detected, the membrane was not adsorbed to $\mathrm{Ce}^{3+}$. The Figure S11i shows the result of XPS splitting of U element. $\mathrm{UO}_{2}{ }^{2+}$ combines with $\mathrm{O}$ on the membrane to form $\mathrm{UO}_{3}$, and the part of $\mathrm{UO}_{2}{ }^{2+}$ also combines with $\mathrm{Cs}^{+}$to form $\mathrm{Cs}_{3} \mathrm{UO}_{4}$, but the peak intensity combined with $\mathrm{Cs}^{+}$is low, so the content is low. There is also $\mathrm{UO}_{2}\left(\mathrm{NO}_{3}\right)_{2} \cdot 6 \mathrm{H}_{2} \mathrm{O}$ compound on the membrane, which is present in the original solution, so it is possible to detect it on the membrane.
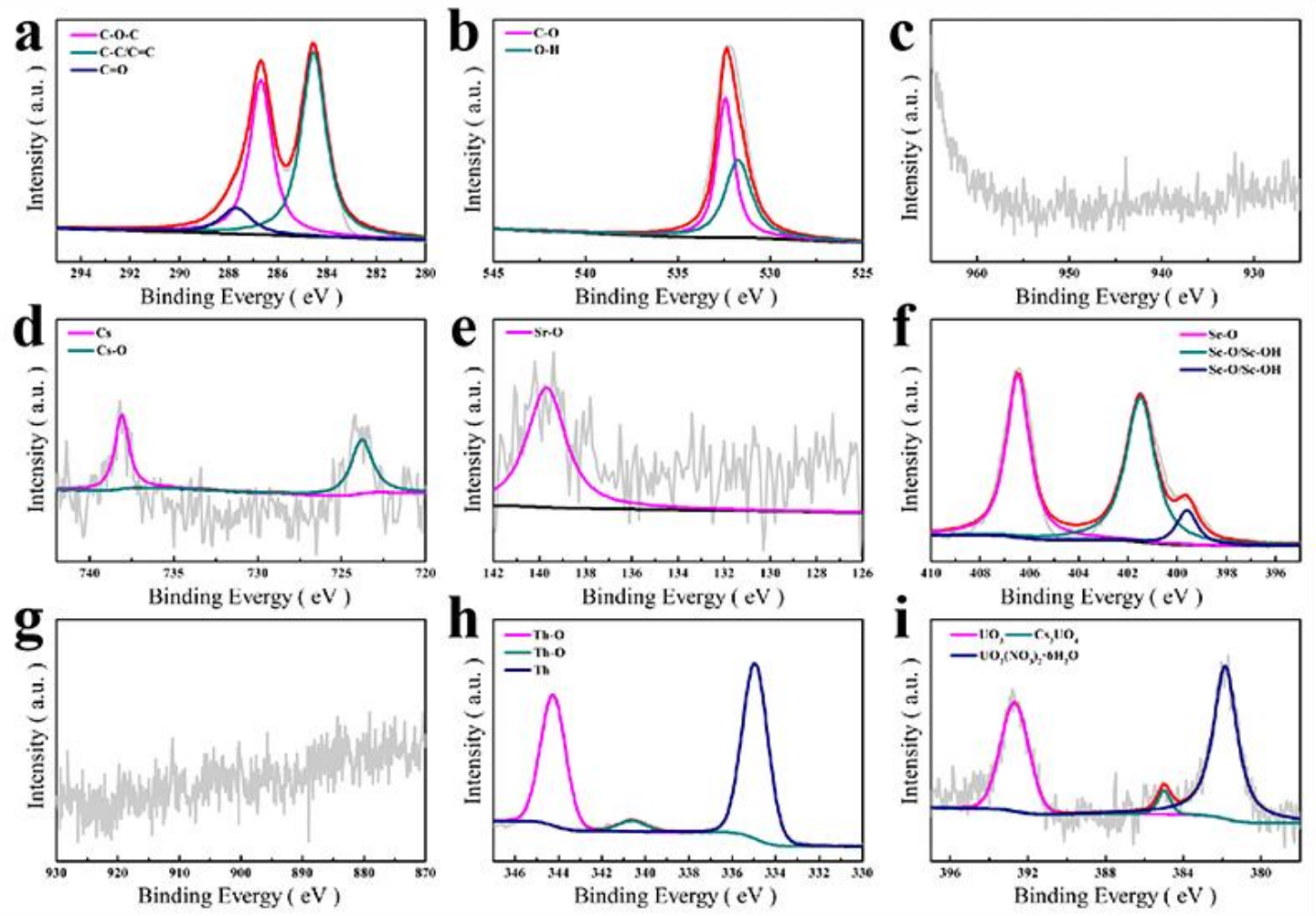

Figure S11. XPS characterization of the separated radioactive element $\mathrm{Cu}$-BTC-MOF intercalated graphene oxide membrane (a. C; b. O; c. Zn; d. Cs; e. Sr; f. Sc; g. Ce; h. Th; i. U) 


\section{References}

[1] Hummers, W.; Offeman, R. Preparation of Graphitic Oxide. J. Am. Chem. Soc. 1958, 80, 1339-1339.

[2] Wang, X.; Ma, X.; Wang, H.; Huang, P.; Du, X.; Lu, X. A Zinc (II) benzenetricarboxylate metal organic framework with unusual adsorption properties, and its application to the preconcentration of pesticides. Microchim. Acta 2017, 184, 3681-3687.

[3] Yaqoob, L.; Noor, T.; Iqbal, N.; Nasir, H.; Zaman, N. Development of Nickel-BTC-MOF-Derived nanocomposites with rGO towards electrocatalytic oxidation of methanol and its product analysis. Catalysts 2019, 9, 856 .

[4] Golsheikh, A. M.; Yeap, G. Y.; Yam, F. K.; Lim, H. S. Facile fabrication and enhanced properties of copperbased metal organic framework incorporated with graphene for non-enzymatic detection of hydrogen peroxide. Synthetuc Met. 2020, 260, 116272. 